\title{
Duchenne Muscular Dystrophy: Canadian Paediatric Neuromuscular Physicians Survey
}

\author{
Hugh J. McMillan, Craig Campbell, Jean K. Mah, on behalf of the Canadian \\ Paediatric Neuromuscular Group
}

\begin{abstract}
Background: Duchenne muscular dystrophy (DMD) is the most common form of muscular dystrophy in childhood. Method: To assess the current care of paediatric DMD patients in Canada, a questionnaire was mailed to 17 physicians who were members of the Canadian paediatric neuromuscular group. Areas of enquiry included; 1) multidisciplinary team composition; 2) means of DMD diagnosis; 3) corticosteroid use; surveillance and management for: 4) orthopaedic, 5) respiratory and 6) cardiac complications and 7) health maintenance (nutrition \& immunizations). Results: Completed surveys were returned by $14 / 17$ (82\%) of physicians. Twelve respondents followed DMD patients. All centres had multidisciplinary teams, including respirology (11/12), child neurology or physiatry (11), physiotherapy (9), occupational therapy (9) and orthopaedic surgery (7). Deflazacort $0.9 \mathrm{mg} / \mathrm{kg} / \mathrm{d} \mathrm{was} \mathrm{used} \mathrm{at} \mathrm{all} \mathrm{centres,}$ which was continued after loss of independent ambulation (11), along with routine calcium and vitamin D supplementation (10). Night splints were prescribed at all centres. Routine surveillance studies included pulmonary function testing (11), sleep studies (10), EKG/echocardiogram (10), bone density (DEXA) scans (10), spine radiography (9), and dietician referral (4). Conclusion: Paediatric DMD patients are receiving relatively consistent care in multidisciplinary clinics across Canada, in accordance with recommended guidelines for DMD.
\end{abstract}

RÉSUMÉ: Dystrophie musculaire de Duchenne : enquête auprès des pédiatres du Canadian Paediatric Neuromuscular Goup. Contexte : La dystrophie musculaire de Duchenne (DMD) est la forme la plus fréquente de dystrophie musculaire dans l'enfance. Méthode : Nous avons posté un questionnaire à 17 médecins membres du Canadian Paediatric Neuromuscular Group afin d'évaluer les soins actuels donnés aux patients d'âge pédiatrique atteints de DMD au Canada. L'enquête portait sur les aspects suivants : 1) la composition des équipes multidisciplinaires; 2) les moyens diagnostiques utilisés pour poser le diagnostic de DMD; 3) l'utilisation de corticostéroïdes; la surveillance et le traitement des complications 4) orthopédiques, 5) respiratoires et 6) cardiaques et 7) les soins de santé usuels (nutrition et immunisations). Résultats : Quatorze des 17 médecins (82\%) ont retourné le questionnaire complété. Douze d'entre eux suivaient des patients atteints de DMD. Tous les centres avaient des équipes multidisciplinaires qui incluaient des pneumologues (11/12), des neurologues ou physiatres pédiatriques (11), des physiothérapeutes (9), des ergothérapeutes (9) et des orthopédistes (7). Tous les centres utilisaient le déflazacort à $0,9 \mathrm{mg} / \mathrm{kg} / \mathrm{j}$. Cette médication était maintenue après le passage au fauteuil roulant (11) ainsi que la prise de routine de calcium et de vitamine D (10). Des attelles nocturnes étaient prescrites dans tous les centres. La surveillance de routine comprenait des épreuves de fonction pulmonaire (11), des études du sommeil (10), un EKG/échocardiogramme (10), mesure de la densité osseuse (DEXA) (10), radiographie de la colonne vertébrale (9) et consultation en diététique (4). Conclusion : Les patients pédiatriques atteints de DMD reçoivent des soins relativement uniformes dans toutes les cliniques multidisciplinaires au Canada, conformément aux recommandations énoncées dans les lignes directrices sur la prise en charge de la DMD.

Can. J. Neurol. Sci. 2010; 37: 195-205

Duchenne muscular dystrophy (DMD) is caused by a mutation in the DMD gene, coding for dystrophin at $\mathrm{Xp} 21$. Inadequate or defective dystrophin protein causes increased muscle membrane fragility, resulting in proximal muscle weakness and marked elevation of serum creatine kinase (CK) levels. Boys with DMD typically present with gait abnormalities (toe-walking, frequent falls, delayed walking, exercise intolerance) between ages 3 - 5 years old, with progressive loss of independent ambulation occurring around 7 - 12 years-of-age. Most boys live until their late 20's, with death resulting from respiratory or cardiac complications. Corticosteroid therapy offers benefit to DMD boys by improving muscle strength and functional test scores ${ }^{1-4}$, prolonging independent ambulation ${ }^{5-9}$,

From the Division of Neurology (HJM), Department of Paediatrics, Children's Hospital of Eastern Ontario, Ottawa; Departments of Paediatrics (CC), Clinical Neurological Sciences and Epidemiology, University of Western Ontario, London, Ontario; Division of Paediatric Neurology (JKM), Department of Paediatrics and Clinical Neurosciences, University of Calgary, Calgary, Alberta, Canada. ReCEIVED April 21, 2009. FinAl Revisions Submitted SePTEMber 1, 2009. Correspondence to: Jean K. Mah, Alberta Children's Hospital, 2888 Shaganappi Trail NW, Calgary, Alberta, T3B 6A8, Canada. 
improving pulmonary function tests ${ }^{1,2}$, and delaying the onset of cardiomyopathy ${ }^{10-12}$ and scoliosis ${ }^{13,14}$.

Due to the progressive nature of DMD, affected individuals require regular monitoring and management of several areas: 1) muscle strength and function; 2) corticosteroid treatment and potential side-effects ${ }^{1,15} ; 3$ ) orthopaedic issues such as soft-tissue contractures, fractures or scoliosis; 4) respiratory complications such as impaired secretion clearance or alveolar hypoventilation; 5) cardiomyopathy; 6) routine health maintenance and 7) social and emotional well being. Ideally patients with DMD should be followed in a comprehensive multidisciplinary neuromuscular clinic in order to minimize the need for patients and families to make multiple visits to various subspecialty clinics. Currently, no Canadian guidelines exist for the care or surveillance of DMD patients. As a result, Canadian clinicians must turn to several other sources for recommendations including: American Academy of Neurology and Child Neurology Society (practice parameter for corticosteroid use in DMD patients) ${ }^{16}$; American Thoracic Society (DMD respiratory care recommendations $)^{17}$, American Academy of Pediatrics (DMD cardiac surveillance recommendations) $)^{18}$ and the European TREAT-NMD (DMD comprehensive care pathway) ${ }^{19}$.

This study was part of a collaborative effort to understand, and ultimately improve, the standard of care for Canadian DMD patients. It was aimed at determining the current clinical management of DMD in paediatric neuromuscular centres across the country in the context of the existing practice guidelines.

\section{METHODS}

A five-page questionnaire was developed by the authors for the purpose of surveying members of the Canadian paediatric neuromuscular group (CPNG) to determine the current standard of care for DMD in Canada. The CPNG is a group of Canadian clinicians (comprised of child neurologists, physiatrists, developmental paediatricians and consultant paediatricians) who have an interest and expertise in caring for children with neuromuscular disorders. All CPNG physicians have a professional affiliation with a tertiary care paediatric hospital or rehabilitation centre. The CPNG first met in 2005, and currently meets twice each year to discuss issues pertaining to patient advocacy and education, current clinical trials, and future research opportunities.

Ethics approval was obtained by the University of Calgary, Conjoint Health Research and Ethics Board (institution of JKM, senior author). The questionnaire contained items summarized into seven main categories pertaining to the care of DMD patients. The $17 \mathrm{CPNG}$ members were mailed a copy of the questionnaire. Members who did not return the questionnaire after two months were contacted twice as a reminder.

\section{RESULTS}

\section{Respondents}

Completed questionnaires were returned by $14 / 17(82 \%)$ of physicians. Twelve respondents indicated that they followed DMD patients. These respondents completed all portions of the questionnaire. All regions of Canada were represented among respondents, including western Canada (5), Ontario (7), Québec (1) and eastern Canada (1). Physicians following DMD patients described their scope of practice as child neurology (8/12), physical medicine and rehabilitation (3/12) or developmental paediatrics (1/12). The mean length of time in practice was 17.8 yrs (range: 4 - 41 yrs).

\section{Multidisciplinary teams}

All respondents (12/12) followed DMD patients in a multidisciplinary care setting. Multidisciplinary teams were comprised of: respirology (11/12), neurology or physiatry $(11 / 12)$, social work (10/12), clinic nurse (9/12), occupational therapy (9/12), physiotherapy (9/12), orthopaedic surgery $(7 / 12)$, cardiology (4/12), general paediatrics (4/12) and/or dietician $(3 / 12)$. Five respondents followed only paediatric DMD patients ( $<18$ yrs old) while seven followed both paediatric and adult DMD patients.

\section{DMD diagnosis}

Genetic testing for dystrophin gene deletions or duplications is the initial diagnostic test ordered at all centres for males presenting with suspected DMD. Centres indicated that they may order 1) multiplex polymerase chain reaction with florescent insitu hybridization probes, or 2) multiple ligation-dependent probe amplification. Complete DMD gene sequencing is used at some centres if initial genetic testing is negative.

Muscle biopsy is performed at $11 / 12$ centres when genetic testing fails to detect a dystrophin gene mutation in a clinically symptomatic male. Genetic counselling was routinely offered at all centres with the aim of: 1) identifying asymptomatic female carriers to facilitate cardiac surveillance, and 2) providing counselling regarding recurrence risk for immediate and extended family members.

\section{Corticosteroids}

Deflazacort $(0.9 \mathrm{mg} / \mathrm{kg} / \mathrm{d})$ was used at all centres. Two respondents indicated that they occasionally used prednisone $(0.75 \mathrm{mg} / \mathrm{kg} / \mathrm{d})$ for treatment of some patients. Respondents indicated some variability with regard to the start of corticosteroid therapy. Most centres used patient's age as a criteria for initiating treatment, around three to five years $(3 / 12)$ or six to eight years (4/12) of age. No centre routinely started corticosteroid therapy after eight-years-old. One centre initiated treatment at the time of DMD diagnosis. Others (3/12) used qualitative functional assessment (i.e. "increased gait difficulties and falling") as a means for treatment initiation. One respondent indicated that treatment was initiated after "discussion with caregiver" at any of the age intervals listed above. Corticosteroid therapy was continued indefinitely by most clinicians (11/12), even after patients became unable to ambulate independently.

Calcium and vitamin D supplementation were routinely recommended at most centres (10/12) when DMD patients started corticosteroid therapy. The dose of recommended calcium supplementation varied from $600-1200 \mathrm{mg} /$ day and vitamin D 200-1000 IU/day. One respondent recommended oral creatine and salbutamol routinely. Whey protein supplements were recommended at another centre.

Routine bone densitometry (DEXA scan; dual energy X-ray absorptiometry) was offered at $10 / 12$ centres. These centres obtained baseline DEXA scans prior to starting corticosteroid 
therapy with surveillance scans completed at 6-24 month intervals. One centre indicated that inadequate resources precluded their ability to obtain bone densitometry. If bone demineralization was identified, $6 / 12$ respondents indicated they would consult endocrinology for possible bisphosphonate therapy (alendronate, pamidronate or zoledronate). Several clinicians (3/12) indicated they would manage bisphosphonate administration independently.

\section{Orthopaedics}

Respondents indicated that orthopaedic surgery was part of over half (7/12) of all multidisciplinary teams. Teams without orthopaedics had either physiatry (3/12), combined physical and occupational therapy (1/12) or physiotherapy alone (1/12) to monitor and treat soft-tissue contractures, assess mobilization and monitor for scoliosis. Overall, allied health members were well represented on most multidisciplinary teams with physiotherapy (9/12) and occupational therapy (9/12) being the most common.

Night splints were routinely offered at all centres (12/12). Splints use was started between ages three to ten years for managing fixed plantar flexion contractures from tight Achilles tendons. Most centres (9/12) offered routine, surveillance radiographs for scoliosis. The onset of surveillance at each centre was not specified.

\section{Respiratory}

Respirology was the most consistent member of the multidisciplinary team (11/12), reflecting the importance of the respiratory system in this progressive muscle disease. The one team lacking respirology indicated that they independently monitored pulmonary function tests (PFT) and referred to respirology when PFT abnormalities were detected.

Routine, anticipatory PFT was offered at 11/12 centres starting between ages 6-11 years-old, and followed at 6-12 month intervals. One centre began PFT testing when DMD patients became symptomatic for respiratory difficulties. Sleep evaluation studies were routinely performed at 10/12 centres. Four respondents indicated that they used age-criteria with the time of the first study varying from 7 years old to 12-16 yearsold. Four respondents offered sleep studies when varying degree of PFT abnormalities were detected (i.e. Forced vital capacity (FVC) $<80 \%$ predicted value or FVC $<1 \mathrm{~L}$ ). Two centres indicate that they offer routine sleep study evaluations when patients present with symptoms of nocturnal hypoventilation (i.e. daytime somnolence, morning headaches and fatigue). Two centres did not offer routine sleep study evaluations. Breath stacking and cough-assist techniques (manual or mechanical) were offered at $9 / 12$ centres.

\section{Cardiac}

Respondents indicated that cardiology was not typically a member of multidisciplinary teams. Teams lacking cardiology $(8 / 12)$ indicated that cardiology referrals were initiated at the time of initial diagnosis (6/8), when surveillance testing indicated electrocardiogram (EKG) or echocardiogram abnormalities (1/8) or when the child reached ten-years-old (lateambulation stage) (1/8).
Electrocardiogram and echocardiograms were most often ordered and followed directly by cardiologists (10/12) whether or not they were part of the DMD multidisciplinary team. Studies were completed at one to two years intervals. Holter monitoring was not part of surveillance studies at any centre and was requested only if there was a clinical history of symptomatic cardiac arrhythmias.

\section{Health Maintenance}

Pneumococcal and influenza vaccinations were routinely recommended by $11 / 12$ respondents. Varicella vaccination was also commonly recommended (10/12). Registered dieticians were routinely involved in patient care at 4/12 centres.

This questionnaire did not ask CPNG members about the timing or details surrounding the discussion of end-of-life issues with DMD patients and families (i.e. long-term mechanical ventilation via tracheostomy versus palliation). All respondents indicated that palliative care was not a routine part of the multidisciplinary clinic team.

\section{Discussion}

As evident from the survey responses, children with DMD appeared to be receiving relatively consistent care across Canada. Based upon the results of the questionnaire, the following discussion will focus on the clinical practise in Canada within the context of existing evidence and/or guidelines.

\section{Multidisciplinary teams}

Multidisciplinary teams provide patients with the benefit of receiving multiple sub-specialist opinions at one clinic visit. This has the effect of 'stream-lining' and optimizing patient care. Respondents have indicated that multidisciplinary clinics are commonplace at all Canadian paediatric tertiary care centres.

\section{Duchenne muscular dystrophy diagnosis}

Duchenne muscular dystrophy males may possess a dystrophin gene with; 1) large deletion (65\% cases); 2) duplication (5-10\% cases) or; 3) point mutations $(25-30 \%$ cases $)^{20}$. Large deletions are readily detectable (98\% cases) by polymerase chain reaction with subsequent florescent in situ hybridization, especially at one of two regions or "hot-spots" (i.e. exons 2-20 and 44-53) where deletions are more likely to occur. Large deletions at other locations, duplications and point mutations will not be detected by this method, and require either multiplex ligation-dependent probe amplification, muscle biopsy or dystrophin gene sequencing for confirmation of diagnosis. Emerging DMD treatments are becoming increasingly tailored to genotype-specific patients (i.e. PTC124 for premature stop codon suppression, or exon skipping using antisense oligonucleotides) and treatment efficacy may hinge upon the type of mutation ${ }^{21}$. Obtaining complete $D M D$ gene sequencing remains a time-consuming process, requiring government preapproval for out-of-province testing in all provinces except Ontario. Fortunately, the results of this survey indicate that Canadian clinicians are pursuing this important step when $D M D$ gene deletions/duplications cannot be identified. 


\section{3) Corticosteroids}

Prednisone and deflazacort are both accepted therapies offered to boys with $\mathrm{DMD}^{16}$. Deflazacort, a synthetic derivative of prednisolone, is not approved by Health Canada for use in DMD patients; however, it can be obtained in this country through a government Special Access Program. In the United States, deflazacort lacks Food and Drug Administration (FDA) approval and must be obtained from out-of-country suppliers.

Eight published randomized controlled trials (Table 1) have demonstrated corticosteroids to improve DMD patient muscle strength and timed function tests. This includes seven randomized trials of prednisone (or prednisolone) versus placebo $^{1-3,22-25}$ and 1 deflazacort versus placebo trial ${ }^{9}$.

Several prednisone doses $(0.3 \mathrm{mg} / \mathrm{kg} ; 0.75 \mathrm{mg} / \mathrm{kg} ; 1.5 \mathrm{mg} / \mathrm{kg})$ and schedules (daily, alternate days; 10 days/month) have been studied. Daily prednisone $0.75 \mathrm{mg} / \mathrm{kg} /$ day is currently accepted as the optimal dose, providing the best balance of therapeutic benefit relative to the potential for steroid-related side-effects ${ }^{16}$. Daily deflazacort at $0.9 \mathrm{mg} / \mathrm{kg} / \mathrm{day}$ is an accepted alternative to prednisone ${ }^{16,19}$, and may offer a more favourable side-effect profile ${ }^{4,5,15}$. There have been two randomized studies directly comparing deflazacort to prednisone $(0.75 \mathrm{mg} / \mathrm{kg})^{15,26,27}$, but the reporting of these trials does not allow conclusive determination of either drugs superiority in DMD.

Mendell et al (1989) ${ }^{1}$ provided the first, large, randomized control of daily prednisone $(0.75 \mathrm{mg} / \mathrm{kg}$ and $1.5 \mathrm{mg} / \mathrm{kg})$ versus placebo. Both high and low prednisone doses were associated with an improvement of timed functional testing, as early as one month after treatment onset. At six months (end-point of study), both prednisone groups showed similar benefit to muscle strength, function and PFT versus placebo. The higher prednisone dose $(1.5 \mathrm{mg} / \mathrm{kg})$ did not confer additional functional benefit, but instead was associated with a higher incidence of side effects such as cushingnoid features, hirsutism, and weight gain. Fenichel et al $(1991)^{3}$ followed these same DMD patients for an additional six months to assess the effect of alternate-day prednisone dosing. The former-placebo group was given prednisone $(2.5 \mathrm{mg} / \mathrm{kg})$ every other day, while the former-daily prednisone groups $(0.75 \mathrm{mg} / \mathrm{kg}$ and $1.5 \mathrm{mg} / \mathrm{kg})$ were changed to alternate-day prednisone $(1.25 \mathrm{mg} / \mathrm{kg}$ and $2.5 \mathrm{mg} / \mathrm{kg})$. Each group demonstrated deterioration of muscle strength with alternate-day treatment at six months.

Griggs et al $(1991)^{2}$ provided a randomized controlled trial comparing two lower doses of daily prednisone $(0.75 \mathrm{mg} / \mathrm{kg}$ and $0.3 \mathrm{mg} / \mathrm{kg}$ ) versus placebo. Again, both prednisone doses was associated with improved muscle strength, function and PFT, as early as ten days after treatment initiation. However, by three months individuals receiving prednisone $0.75 \mathrm{mg} / \mathrm{kg}$ were significantly stronger than the $0.3 \mathrm{mg} / \mathrm{kg}$ group. This study was influential at establishing prednisone $0.75 \mathrm{mg} / \mathrm{kg}$ as the recommended treatment dose for DMD patients in the United States ${ }^{16}$; however it is noteworthy that the $0.75 \mathrm{mg} / \mathrm{kg}$ dose was associated with a higher incidence of side-effects.

Four additional randomized, placebo-controlled studies have demonstrated a clear therapeutic benefit to prednisone: Beenakker et al $(2005)^{25}$ studied prednisone $0.75 \mathrm{mg} / \mathrm{kg}$ for first ten days per month; Backman et al (1995) $)^{23}$ used daily prednisolone $0.35 \mathrm{mg} / \mathrm{kg}$; Rahman et $\mathrm{al}^{24}$ studied daily prednisolone $0.75 \mathrm{mg} / \mathrm{kg}$; and Griggs et al (1993) ${ }^{22}$ used daily prednisone $0.3 \mathrm{mg} / \mathrm{kg} \& 0.75 \mathrm{mg} / \mathrm{kg}$. All studies demonstrated improvement in muscle strength and timed functional test in the steroid group relative to placebo. Griggs' study was the longest in duration; it showed that the initial benefit seen with daily prednisone therapy persisted at 18 months, and the addition of azathioprine to some patients during the last 12 months of treatment did not confer any additional benefits ${ }^{22}$.

Deflazacort has been the subject of two controlled trials comparing to placebo. The first non-randomized trial ${ }^{4}$ compared daily deflazacort $(1 \mathrm{mg} / \mathrm{kg})$ to placebo for nine months. Deflazacort-treated patients were stronger by three months, with improvement in their timed Gower's manoeuvre evident by six months, and the differences increased by nine months. Side effects of deflazacort included behaviour changes, increased appetite, cushingnoid appearance and hirsutism. Excessive weight gain (i.e. $>20 \%$ of baseline) was less pronounced with daily deflazacort $(7 \%)$ relative to studies with daily prednisone, but this data has yet to be confirmed by a large direct comparison trial $^{16}$. The second randomized trial ${ }^{9}$ provided a longer-term (24 month) evaluation of alternate day deflazacort $(2 \mathrm{mg} / \mathrm{kg})$ versus placebo. This group confirmed superior muscle strength and functional testing in the deflazacort group (within six months) which was sustained at 24 months. In this study, deflazacorttreated patients had an average weight gain of only $11.4 \%$ compared to $7.5 \%$ for the placebo group.

Only two small trials have directly compared daily deflazacort $(0.9 \mathrm{mg} / \mathrm{kg})$ with daily prednisone $(0.75 \mathrm{mg} / \mathrm{kg})^{15,26,27}$. Bonifati et $\mathrm{al}^{15}$ reported no statistical difference in the efficacy of the two drugs after 12 months treatment, and a trend in less weight gain was seen with deflazacort (9\% compared to $21.3 \%$ increase with prednisone $)^{15}$. The second trial was never published beyond interim results ${ }^{26,27}$. Clearly there is a need for a large, multi-centre trial directly comparing the therapeutic benefit and side-effect profile of deflazacort and prednisone. Until then, systematic reviews ${ }^{28}$, meta-analysis ${ }^{29}$ and medical societies $^{16}$ have recommended either daily prednisone $(0.75 \mathrm{mg} / \mathrm{kg})$ or deflazacort $(0.9 \mathrm{mg} / \mathrm{kg})$ for maintaining muscle strength and function for individuals with DMD.

\section{Corticosteroids: Benefits beyond strength}

There is mounting evidence that the benefit of corticosteroids extends beyond skeletal muscle. Prednisone and deflazacort have been shown to improve pulmonary function tests ${ }^{1,2,13}$; delay the onset and/or decrease the incidence of cardiomyopathy ${ }^{10-12}$; and scoliosis ${ }^{13,14}$. Biggar and his colleagues provided evidence from both prospective ${ }^{13}$ and retrospective studies ${ }^{5,10}$, including one of the best longitudinal prospective data on a cohort of DMD boys. Fifty-four individuals received either daily deflazacort $0.9 \mathrm{mg} / \mathrm{kg}$ (30 patients) or no treatment (24 patients), and were followed for a mean of 7.2yrs (treatment group) and 7.4yrs (control group). The results showed that deflazacort-treated DMD boys had a striking improvement in muscle strength, pulmonary function as well as a marked reduction in the incidence of scoliosis. The mean age that deflazacort-treated patients stopped walking was 12.3yrs (versus 9.8 yrs in controls). The deflazacort group had a mean FVC of $72 \%$ predicted (range $50-88 \%$ ) versus $35 \%$ predicted (range: $20-48 \%$ ) for controls. Scoliosis (curve $>20^{\circ}$ ) was much less common in deflazacort-treated boys $(5 / 30,17 \%)$ compared to controls $(16 / 24,67 \%)^{13}$. Deflazacort-related side- 
effects in the treatment group included weight gain (mean of 3.7 $\mathrm{kg}$ more than control group), osteopenia and symptomatic stress fractures $(10 \%)$, and asymptomatic cataracts $(33 \%)^{13}$.

\section{Corticosteroids: When to initiate therapy}

There are no randomized controlled trials on the optimal age for initiating corticosteroid therapy in DMD. This lack of information may explain the variability seen among our survey respondents as to when steroid therapy is initiated. Most studies have included corticosteroid use for DMD boys between 5-15 years old ${ }^{1-3}$. One small, open-label, prospective cohort study examined younger (2-4 yrs old) DMD boys treated with prednisone (initially $0.75 \mathrm{mg} / \mathrm{kg}$ daily; x 2 weeks; then 1.25 $\mathrm{mg} / \mathrm{kg}$ on alternate days). After 55 months treatment, all patients in the prednisone group were still able to rise from the floor, whereas $2 / 3$ of the control patients had lost that ability ${ }^{30}$. Another prospective uncontrolled study of six boys under five years of age treated with intermittent prednisone (ten days per month) reported an improvement of muscle strength and functional testing, compared to the natural history of untreated young DMD boys ${ }^{31}$. The sample size for these two studies was extremely small (five to six patients each). This finding points to the need for future studies to better delineate the optimal age for initiating corticosteroid treatment.

\section{Corticosteroids: When to discontinue therapy}

The issue of when to discontinue corticosteroid therapy is also controversial. Our survey found that almost all responding Canadian neuromuscular specialists continued deflazacort indefinitely for DMD individuals even after losing independent ambulation. This practice may be due to the results of several retrospective, open-labelled cohort studies indicating deflazacort treatment to be associated with delayed onset of late complications (listed above). Continuing corticosteroid therapy for the potential benefit of delaying cardiomyopathy and respiratory failure must be balanced with ongoing bone demineralization, a serious concern for the non-ambulatory, nonweight bearing patient. The potential for substantial weight gain and its accompanying morbidity (i.e. increased incidence of obstructive sleep apnea, worsening hypoventilation, increased challenge for caregivers surrounding patient transfers) are other reasons for caution. Further prospective studies are needed to evaluate the risk-benefit ratio of corticosteroid use in nonambulatory DMD males.

\section{Corticosteroids \& monitoring bone health}

Ensuring optimal bone health with adequate calcium and vitamin D intake is an important consideration, since corticosteroid therapy appears to increase the risk of vertebral fracture in DMD patients, which may occur following minor or no identifiable trauma ${ }^{32}$. A recent DMD workshop (Cincinnati, USA) $)^{33}$ acknowledged that while vitamin $\mathrm{D}$ and calcium contribute to bone health, supplementation has not been proven to reduce the risk of low-impact fractures among DMD boys. Experts recommended that clinicians check serum 25hydroxyvitamin D levels annually and offer supplementation for levels $<20 \mathrm{ng} / \mathrm{mL}^{33}$. In contrast, current European guidelines recommend routine supplementation with calcium (4-8 yrs old: 800mg/d; $9-18$ yrs old: $1300 \mathrm{mg} / \mathrm{d})$ and vitamin D (400 IU/d) if dietary intake is inadequate ${ }^{19}$. Our survey demonstrates that most Canadian DMD centres follow the European guidelines by recommending vitamin $\mathrm{D}$ and calcium supplementation at the initiation of steroid therapy.

Expert recommendations from another DMD workshop (Birmingham, UK) ${ }^{32}$ recommended bone densitometry or DEXA scan (dual energy X-ray absorptiometry) in all DMD patients at one to two year intervals ${ }^{32}$. However, there is no consensus as to what skeletal sites should be studied (i.e. hip, femur, lumbar vertebrae, total body) or what Z-score threshold might trigger the initiation of bisphosphate therapy ${ }^{33}$. Duchenne muscular dystrophy boys have delayed growth and puberty as well as diminished muscle mass, all of which may contribute to potentially lower age-matched bone-density scores ${ }^{33}$. Although most Canadian DMD centres obtain routine bone density studies (every 6-24 months), further studies are needed to identify reliable predictors for non-traumatic fractures in DMD patients $^{33}$.

\section{Other therapies}

Limited benefits for DMD patients has been demonstrated with several other drugs such as creatinine monohydrate ${ }^{34}$, salbuterol $^{35,36}$ and cyclosporine ${ }^{37}$. No therapeutic benefit has been found with use of: anabolic steroids (oxandrolone) $)^{38}$, allopurinol $^{39}$, glutamine ${ }^{40}$, selenium or vitamin $\mathrm{E}^{41}$. A clinical trial of PTC124 a nonsense mutation read-through agent (Ataluren $^{\mathrm{TM}}$, PTC Therapeutics Inc., Cambridge, MA) is currently underway for DMD and Becker Muscular Dystrophy (BMD) boys known to have a nonsense mutation (premature stop codon). If effective, this drug would offer benefit to only a subgroup of DMD patients. In our study only one respondent routinely uses creatine monohydrate and salbuterol, reflecting the need for more studies to determine their clinical relevance.

\section{Orthopaedics}

Scoliosis is a common complication of $\mathrm{DMD}^{20,42}$. Most individuals with DMD develop scoliosis with loss of independent ambulation ${ }^{14}$. An early, natural history study of 33 DMD boys who did not receive spinal fusion, revealed their scoliosis to progress to a mean curvature of $89.6+33.7^{\circ}$ at the time of death ${ }^{42}$. Some experts have recommended surveillance spine radiography be conducted every six months during adolescence $^{43}$, however, no consensus guidelines exist. Scoliosis contributes to the deterioration of respiratory function in DMD patients, with an estimated $4 \%$ loss of forced vital capacity for every $10^{\circ}$ progression of the Cobb angle ${ }^{44}$. Scoliosis surgery delays further deterioration of pulmonary function and may improve long-term survival ${ }^{45}$. It also improves patient comfort and facilitates sitting, transfer, and personal care. However, scoliosis surgery may not reverse the loss of vital capacity $^{46}$.

Due to progressive weakness, DMD patients do not benefit from non-surgical interventions such as bracing for scoliosis ${ }^{47}$. Instead, spinal fusion is often performed at early stages (with radiographic deformity as slight as $\left.10-20^{\circ}\right)^{48}$. The rate of all operative and post-operative complications (i.e. skin infection or pneumonia, pleural effusion, cardiac arrest, need for long-term 
ventilation and tracheostomy, hardware malfunction) in DMD boys undergoing scoliosis surgery is approximately $10-30 \% 48,49$.

A FVC of $30-40 \%$ was once referred to as a "cut-off" for DMD scoliosis surgery, due to increased cardiorespiratory morbidity associated with further respiratory weakness however, a recent retrospective study led to a revision of this thinking ${ }^{49}$. Marsh et $\mathrm{al}^{49}$ reviewed the complications of scoliosis surgery among 30 DMD patients with a range of FVC (18-60\%). Patients were grouped according to their pulmonary function: 17 patients had FVC $>30 \% ; 13$ patients were $<30 \%$. The two groups demonstrated no difference in complication rate, time in the operating suite, duration of post-operative ventilator support or duration of inpatient stay. Other studies have demonstrated clinical benefit for scoliosis surgery in DMD patients with severe respiratory muscle weakness, including those with $\mathrm{FVC}<30 \%$ predicted ${ }^{49}$, although the best prognosis occurs for patients with $\mathrm{FVC}>40 \%{ }^{42}$.

The American Thoracic Society (ATS) has stated that FVC values alone should not represent an absolute contraindication to scoliosis surgery ${ }^{17}$. Prior to surgery, all DMD patients should be evaluated by a respirologist $\mathrm{t}^{17}$, receive a complete cardiac evaluation including echocardiogram even if no symptoms of cardiac failure are clinically evident ${ }^{16}$, and have pre-operative consultation from anaesthesiology.

\section{Respiratory}

Duchenne muscular dystrophy patients experience a gradual loss of respiratory muscle strength over time. The onset of hypoventilation and subsequent need for ventilation is associated with loss of independent ambulation ${ }^{50}$. Patients first develop ineffective and weak cough followed by increasing alveolar hypoventilation and eventually respiratory failure, which is the cause of death for roughly $90 \%$ of DMD patients ${ }^{20}$.

The ATS recommends that DMD patients should be seen by a respirologist for anticipatory medical guidance and baseline pulmonary function testing early in the course of their disease (i.e. age 4-6 yrs) ${ }^{17}$. Follow-up frequency should be increased to six monthly intervals, either: 1) beginning at 12 years-of-age, 2) after loss of independent ambulation, or 3) after decline in FVC $<80 \%$ predicted ${ }^{17}$. Patients requiring use of mechanically assisted airway clearance therapy or mechanically assisted ventilation should also be seen by respirology every three to six months.

Our survey indicated that sleep studies are not widely performed across Canadian centres, in part related to inadequate resources. The ATS recommends annual evaluation for sleepdisordered breathing for all DMD patients starting from the time that they are wheelchair-bound and/or when clinically indicated. This should include annual polysomnography or overnight pulse oximetry with continuous $\mathrm{CO}_{2}$ monitoring ${ }^{17}$. Early detection and treatment of nocturnal hypoventilation and $\mathrm{CO}_{2}$ retention may improve daytime quality of life and delay the onset of pulmonary hypertension. Nocturnal non-invasive ventilation using bi-level positive airway pressure (BiPAP) is typically the first step in providing respiratory support for DMD patients with deteriorating respiratory function. The advent of non-invasive ventilation in the 1990's has significantly increased the life expectancy of DMD males, with the mean life expectancy now at 25.3 years $^{51}$.
Individuals with DMD are at increased risk of atelectasis and subsequent pneumonia when they are no longer able to generate a sufficient cough to clear their airways. As DMD patients are typically unaware of this issue, cough effectiveness should be assessed regularly by measuring maximal inspiratory and expiratory pressures, peak cough expiratory flow, and forced vital capacity ${ }^{17}$. Almost all Canadian centres follow pulmonary functions routinely, with most offering cough assist and breathstacking support. Current recommendations suggest that cough assist devices be employed for all DMD patients with peak cough flow $<270 \mathrm{~L} / \mathrm{min}$ and/or maximal expiratory pressure less than $60 \mathrm{~cm} \mathrm{H}_{2} \mathrm{O}^{17}$.

\section{Cardiac}

Nigro et al $(1990)^{52}$ has provided one of the best studies documenting the natural history of cardiac disease among DMD patients. A group of 328 DMD patients were followed between 3-11 years. Pre-clinical cardiac involvement was reported in $25 \%$ of patients under six-years-old, increasing to $59 \%$ between six to ten-years-old. Clinically apparent cardiomyopathy was first noted after age ten years, and was present in all DMD patients over 18-years-old. Cardiac failure is the cause of death in $10-20 \%$ of DMD males ${ }^{50}$. Right ventricular failure may also develop from respiratory failure and pulmonary hypertension.

The onset of dilated cardiomyopathy may precede clinical signs of heart failure (i.e. chest pain, palpitations or dyspnea) by several years. Symptoms of early cardiac failure may be more difficult to recognize in DMD patients due to skeletal muscle weakness and overall physical inactivity. One retrospective study suggests that early corticosteroid therapy may have the added benefit of delaying the onset of left ventricular (LV) dysfunction ${ }^{12}$. Another randomized controlled trial demonstrated a beneficial effect associated with the early, prophylactic use of the angiotensin converting enzyme inhibitor (ACE-I) perindopril ${ }^{53}$. The onset and subsequent progression of left ventricle dysfunction was less in DMD boys treated with prophylactic perindopril compared to placebo-controls ${ }^{53}$.

After echocardiogram evidence of cardiomyopathy becomes apparent, sustained improvement in LV dysfunction has been reported in several retrospective studies with the use of another ACE-I (enalapril) ${ }^{54}$ or combination of an ACE-I (enalapril or lisinopril) and a $\beta$-blocker (metoprolol or bisoprolol) ${ }^{55,56}$. The results from these studies, however promising, must be interpreted with caution. Data was collected retrospectively and did not compare treatment groups to a no-treatment control or natural history population. Furthermore, the studies did not specify if DMD patients were previously or currently treated with corticosteroids. Importantly, randomized, placebocontrolled trials may never be done in this area. Since ACE-I have been demonstrated to be beneficial for the treatment of adult non-DMD cardiomyopathy ${ }^{57}$, the withholding of these potentially beneficial medications for a control group of DMD boys with cardiomyopathy would be difficult to justify on moral grounds.

Currently, the American Academy of Pediatrics (AAP) ${ }^{18}$ recommends that ACE-I, $\beta$-blocker or diuretics should be considered when signs or symptoms of cardiac dysfunction are identified $^{18}$. Additional data will be required before routine, early, or prophylactic ACE-I therapy be recommended. Expert 
Table 1: Published data on DMD patient care: levels of evidence (American Academy of Neurology Criteria) ${ }^{58}$

Corticosteroid use (DMD boys; age 5-15 yrs old):

Prednisone beneficial to muscle strength, motor function tests Deflazacort beneficial to muscle strength, motor function tests

Prednisone $(0.75 \mathrm{mg} / \mathrm{kg} / \mathrm{d}) \&$ deflazacort $(0.9 \mathrm{mg} / \mathrm{kg} / \mathrm{d})$ equally effective Deflazacort has less weight gain (versus prednisone)

Corticosteroids prolongs time of independent ambulation

Corticosteroids improve pulmonary function tests relative to placebo

Corticosteroids delay onset of cardiomyopathy

Corticosteroids delay onset of scoliosis

Calcium and vitamin D supplementation reduces bone demineralization Bone densitometry (DEXA scan) every 1-2 yrs

\section{Corticosteroid use (DMD boys; age $<5$ yrs):}

Prednisone prolongs proximal strength (ability to get up from floor)

Prednisone (intermittent) improves motor function testing

Scoliosis:

Scoliosis surgery (Cobb angle $>20^{\circ}$ ) improves FVC and peak expiratory flow

\section{Respiratory:}

Respirology evaluation (inc. exam, pulmonary function test) at 4-6 yr old Respiratory evaluation q6mos at $12 \mathrm{yr}$ old, when not walking, or $\mathrm{FVC}<80 \%$

Annual polysomnography with continuous $\mathrm{CO}_{2}$ monitor or overnight oximetry

Cough-assist device should be considered if impaired airway clearance,

peak cough flow $<270 \mathrm{~L} /$ min or max expiratory pressure $<60 \mathrm{~cm} \mathrm{H}_{2} \mathrm{O}$

Cardiac:

Annual cardiac evaluation (exam, EKG, echo) beginning at school-age Bi-annual cardiac evaluation until 10yrs old, annual after 10yrs old

Enalapril therapy of DMD cardiomyopathy results in sustained left ventricle function

Combined ACE-I $+\beta$-blocker therapy results in sustained left ventricle function

Early, prophylactic perindopril may delay onset \& progression of Left ventricle dysfunction

Routine holter monitoring only if cardiac dysfunction detected

Health maintenance:

Routine nutrition monitoring and /or deflazacort use may reduce weight-gain

Routine pneumococcal, varicella, influenza vaccines (prior to steroids)

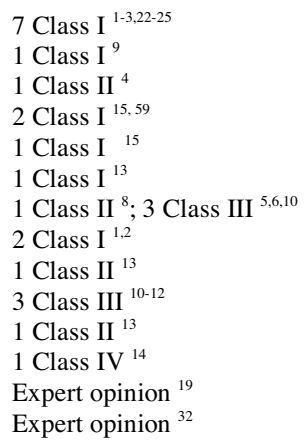

Classification of studies:

Class I: $\quad$ Evidence provided by prospective, randomized control trial with marked outcome assessment and all of:

i) primary outcome clearly defined;

ii) exclusion/inclusion criteria clearly defined;

iii) adequate account of drop-outs / crossover patients that are sufficiently low to not bias results;

iv) relevant baseline characteristics between treatment and placebo groups.

Class II: $\quad$ Evidence provided by prospective matched group cohort study in representative population with marked outcome assessment that meets ( $\mathrm{i}$ - iv, above) $\underline{\mathrm{OR}}$ randomized control trial in representative population lacking $1 \mathrm{criteria}$ (i - iv)

Class III: $\quad$ Evidence for all other control trials, including well-defined natural history control or patients serving as own

controls in a representative population where outcome assessment is independent of patient treatment.

Class IV: $\quad$ Evidence for uncontrolled studies, case series, case reports or expert opinions.

Translation of evidence to recommendations:

Level A: $\quad$ Establishes treatment as effective/ineffective/harmful for specified population

Requires at least 1 convincing Class I study or at least 2 Class II studies

Level B: $\quad$ Establishes treatment as probably effective/ineffective/harmful for specified population

Requires at least one convincing Class II study or at least 3 consistent Class III studies

Level C: $\quad$ Establishes treatment as possibly effective/ineffective/harmful for specified population

$\begin{array}{ll}\text { Level U: } & \text { Requires at least } 2 \text { convincing \& consistent Class III studies } \\ & \text { Data is inadequate or conflicting given current knowledge }\end{array}$ 
opinion from American and European groups recommend that all DMD patients receive a complete cardiac assessment at diagnosis, every two years until age ten years old, and annually thereafter ${ }^{18,50}$. Although paediatric cardiologists are frequently not members of Canadian DMD multidisciplinary teams, almost all centres refer patients to cardiology at the time of initial diagnosis. Cardiac follow-up becomes more frequent with advancing age, when the risk of underlying cardiomyopathy increases. Cardiology consultation may operate outside of the team due to the need for concomitant, EKG and echocardiogram testing that may not be easily integrated into the team visit. Given the need for these important surveillance studies, many Canadian centres opt to schedule cardiology visits at separate times.

Holter monitoring is not a routine part of cardiac surveillance; however, the AAP recommends periodic Holter monitoring for: 1) DMD patient with symptoms of possible cardiac arrhythmia (e.g. palpitations, chest pain), or 2) DMD patients with

Table 2: Summary of suggested DMD patient management: clinical practice guidelines ${ }^{16-19,50}$

\begin{tabular}{|c|c|c|c|}
\hline $\begin{array}{c}\text { Key Stages \& } \\
\text { Intervention }\end{array}$ & $\begin{array}{l}\text { At diagnosis or early stage } \\
\text { (2 to } 7 \text { years old })\end{array}$ & $\begin{array}{c}\text { Loss of ambulation / adolescence } \\
\text { (8 to } 16 \text { years old) }\end{array}$ & $\begin{array}{c}\text { Later stages } \\
(>16 \text { years old })\end{array}$ \\
\hline$\frac{\text { Patient / family }}{\underline{\text { knowledge: }}}$ & $\begin{array}{l}\text { Discuss: } \\
\text { DMD natural history, genetics } \\
\text { Role of corticosteroids } \\
\text { Research studies } \\
\text { Genetic counselling referral } \\
\text { (Carrier testing if indicated) } \\
\text { Provide written material, websites } \\
\text { and peer support information } \\
\text { Muscular Dystrophy Canada (MDC) } \\
\text { contact information }\end{array}$ & $\begin{array}{l}\text { Discuss: } \\
\text { Nutrition } \\
\text { Complications of DMD (scoliosis, } \\
\text { cardiac, and respiratory) } \\
\text { Complications of corticosteroids } \\
\text { Symptoms of nocturnal hypoventilation } \\
\text { Options for long-term ventilation } \\
\text { assistance (i.e. BiPAP, CPAP) } \\
\text { Medical management of } \\
\text { cardiomyopathy (if present) } \\
\text { School / social supports } \\
\text { Respite / financial issues } \\
\text { Adolescent needs, quality of life issues } \\
\text { Review previous topics }\end{array}$ & $\begin{array}{l}\text { Discuss: } \\
\text { Transition to adult care } \\
\text { Options for long-term } \\
\text { ventilation support } \\
\text { Nutritional support (G-tube) } \\
\text { End-of-life counseling and } \\
\text { advance medical directive } \\
\text { Review previous topics }\end{array}$ \\
\hline$\underline{\text { Professional support }}$ & $\begin{array}{l}\text { Medical consultations: } \\
\text { Genetics } \\
\text { Respirology } \\
\text { Orthopedics (night splints, scoliosis) } \\
\text { Cardiology } \\
\text { Neurology / Physiatry } \\
\text { Ophthalmology (cataracts) } \\
\text { Allied health support: } \\
\text { Clinic Nurse Dietician } \\
\text { Physiotherapist Psychologist } \\
\text { Occupational therapy } \\
\text { Social worker } \\
\text { MDC community liaison }\end{array}$ & $\begin{array}{l}\text { Medical consultations (as before, plus) } \\
\text { Endocrinology (osteoporosis, } \\
\text { bisphosphonate therapy) } \\
\text { Teach: } \\
\text { Chest physiotherapy to family } \\
\text { Breath stacking, cough assist } \\
\text { Seating for wheelchair } \\
\text { Passive \& active exercises }\end{array}$ & $\underline{\text { Medical consultations (as before) }}$ \\
\hline Medical therapy: & $\begin{array}{l}\frac{\text { Immunizations: }}{\text { Varicella vaccine }} \\
\text { Pneumococcal vaccine } \\
\text { Influenza vaccine } \\
\text { Corticosteroids } \\
\text { Deflazacort }(0.9 \mathrm{mg} / \mathrm{kg} / \mathrm{d}) \text { or } \\
\text { Prednisone }(0.75 \mathrm{mg} / \mathrm{kg} / \mathrm{d}) \\
\text { Physiotherapy: } \\
\text { Passive stretching, night splints } \\
\text { Bone health: } \\
\text { Calcium supplementation } \\
\text { Vitamin D supplementation } \\
\text { Other: } \\
\text { Behavioral intervention } \\
\text { Weight management }\end{array}$ & $\begin{array}{l}\text { Review previous topics } \\
\text { Interventions (as required): } \\
\text { Angiotensin converting enzyme inhibitor } \\
\text { and/or beta-blocker (cardiomyopathy) } \\
\text { Diuretics (congestive heart failure) } \\
\text { Antibiotics (respiratory tract infections) } \\
\text { Sitting ankle-foot orthosis } \\
\text { Scoliosis surgery (pre-op Cardiology, } \\
\text { Respirology \& Anesthesiology consults) }\end{array}$ & $\underline{\text { Review previous topics }}$ \\
\hline $\begin{array}{l}\text { Monitoring: } \\
\text { Clinical: }\end{array}$ & $\begin{array}{l}\text { Weight and height, BP monitoring } \\
\text { Formal muscle function, strength tests } \\
\text { ECG, electrocardiogram (q } 2 \text { yrs) } \\
\text { Pulmonary function testing } \\
\text { Wrist x-ray for bone age } \\
\text { Bone densitometry study } \\
\text { Urine glucose } \\
\text { 25-hydroxyvitamin D level }\end{array}$ & $\begin{array}{l}\text { Same as before, except: } \\
\text { ECG, echocardiogram (q } 1 \text { yr) }>10 \text { yr old }\end{array}$ & $\underline{\text { Same as before }}$ \\
\hline Clinical review: & 6-12 months & 3-6 months & 1-3 months \\
\hline
\end{tabular}


significant cardiomyopathy ${ }^{18}$. A prospective, cohort study revealed that frequent ventricular premature complexes $(>6 /$ hour) and/or left ventricular dysfunction were associated with an increased risk of sudden death ${ }^{60}$. The fibrous replacement and/or dilatation of myocardial muscle fibres have been postulated to be the cause of ventricular tachyarrhythmia in such patients ${ }^{60}$. Early detection and institution of medical therapy (antiarrhythmics or ACE-I) may be of potential therapeutic benefit.

\section{Cardiac complications among female carriers}

Female DMD carriers may present with muscle weakness and/or cardiomyopathy. Dilated cardiomyopathy may be the first and only manifestation of a DMD gene mutation in some female carriers, as marked cardiac involvement may occur in the absence of skeletal muscle weakness ${ }^{61}$. Serum CK is not a reliable means of screening for potential female carriers of mutated $D M D$ genes, since elevated CK (2-10x normal) was only seen in 53\% females with DMD-relatives and 30\% females with BMD-relatives ${ }^{62}$.

Hoogerwaard et al (1999) also provided one of the best prospective cohort studies of female DMD carriers; obligate female carriers (ages 18-58 yrs old) who had male relatives affected by either DMD (84) or BMD (43). At the time of evaluation, most carrier females (76\%) were asymptomatic, while others reported myalgias or cramps $(5 \%)$ or mild-tomoderate $(9.5 \%)$ weakness on strength testing. Complete cardiac evaluation of these women with male DMD relatives found that $8 \%(7 / 84)$ had echocardiogram evidence for dilated cardiomyopathy and 19\% (16/84) had left ventricle dilatation. Results for female carriers with male BMD relatives were similar, except that echocardiogram evaluation demonstrated that none had dilated cardiomyopathy, and 16\% (7/35) had left ventricular dilation $^{62}$.

In light of female carriers having increased risk for skeletal and cardiac muscle involvement, the AAP recommends all female carriers to receive an initial cardiology assessment by late-adolescence, with repeat cardiac evaluation subsequently every five years, beginning at 25-30 years old ${ }^{18}$.

\section{Health Maintenance}

The ATS recommends that all DMD patients receive pneumococcal vaccination and annual influenza vaccination ${ }^{17}$. Our survey results are in keeping with this recommendation. Most clinicians also advise varicella vaccination prior to corticosteroid therapy. No randomized controlled study of corticosteroid use in DMD patients has reported an increased risk of infection or instances of severe infection ${ }^{1-4,9,15}$.

Adolescent DMD patients have a higher incidence (44\%) of malnutrition or obesity ${ }^{63}$. Dramatic increase in appetite associated with corticosteroid use results in rapid weight gain for many DMD patients, as defined by a $10-20 \%$ increase above baseline weight within 12 months ${ }^{15}$. Early dietary consultation has the potential to temper the steroid-associated weight gain; one randomized controlled trial with strict nutritional monitoring showed no significant weight gain in deflazacort-treated boys relative to placebo ${ }^{4}$. Many centres rely upon occupational therapy to screen for dysfunctional swallowing. Although occupational therapy is well suited in many instances to evaluate the mechanics of swallowing, dietician involvement may also help to eliminate or avoid certain types of foods in patients with early swallowing dysfunction.

\section{Conclusions}

Children with DMD are receiving relatively consistent care across Canada in multidisciplinary clinics. Duchenne muscular dystrophy management is largely in keeping with the recommendations with regard to corticosteroid $\mathrm{use}^{16}$ and surveillance for cardiac and respiratory complications ${ }^{17,18}$. By describing the current clinical practice, existing scientific evidence and expert opinions, we hope to provide a comprehensive context for elevating the standard of practice in Canadian neuromuscular clinics and improve the care of DMD patients.

\section{ACKNOWLEDGEMENTS}

This study was funded by the Stichting Porticus Foundation and the Cooperative International Neuromuscular Research Group (PI: Dr. J.K. Mah).

Canadian Paediatric Neuromuscular Group members: Brenda Banwell M.D., Hospital for Sick Children, Toronto; Doug Biggar M.D., Bloorview-McMillan Children's Centre, Toronto; Craig Campbell M.D., MSc., Children's Hospital of Western Ontario, London; Joseph Dooley M.B, IWK Health Centre, Halifax; Gillian Hogan M.B, B.Ch., B.A.O., D.Ch., Erinoak Children's Centre, Mississauga; Pierre Jacob M.D, Children's Hospital of Eastern Ontario, Ottawa; Hanna Kolski M.D., Stollery Children's Hospital, Edmonton; Noel Lowry M.D., Royal University Hospital, Saskatoon; Jean K. Mah M.D., MSc., Alberta Children's Hospital, Calgary; Anna McCormick M.D., Children's Hospital of Eastern Ontario, Ottawa; Hugh McMillan M.D., M.Sc, Children's Hospital of Eastern Ontario, Ottawa; Maryam Oskoui M.D., Montreal Children's Hospital, Montréal; Chantal Poulin M.D., Montreal Children's Hospital, Montréal; Bev Prieur M.D., Alberta Children's Hospital, Calgary; Kathryn Selby M.D., BC Children's Hospital, Vancouver; Garth Smith M.B.B.S., Kingston General Hospital, Kingston; Mark Tarnapolski M.D., PhD., McMaster Children's Hospital, Hamilton; Jiri Vajsar M.D., Hospital for Sick Children, Toronto; Grace Yoon M.D., Hospital for Sick Children, Toronto.

\section{REFERENCES}

1. Mendell JR, Moxley RT, Griggs RC, Brooke MH, Fenichel GM, Miller JP, et al. Randomized, double-blind six-month trial of prednisone in Duchenne's muscular dystrophy. N Engl J Med. 1989;320(24):1592-7.

2. Griggs RC, Moxley RT, 3rd, Mendell JR, Fenichel GM, Brooke MH, Pestronk A, et al. Prednisone in Duchenne dystrophy. A randomized, controlled trial defining the time course and dose response. Clinical Investigation of Duchenne Dystrophy Group. Arch Neurol. 1991;48(4):383-8.

3. Fenichel GM, Mendell JR, Moxley RT, 3rd, Griggs RC, Brooke $\mathrm{MH}$, Miller JP, et al. A comparison of daily and alternate-day prednisone therapy in the treatment of Duchenne muscular dystrophy. Arch Neurol. 1991;48(6):575-9.

4. Mesa LE, Dubrovsky AL, Corderi J, Marco P, Flores D. Steroids in Duchenne muscular dystrophy--deflazacort trial. Neuromuscul Disord. 1991;1(4):261-6.

5. Biggar WD, Gingras M, Fehlings DL, Harris VA, Steele CA. Deflazacort treatment of Duchenne muscular dystrophy. J Pediatr. 2001;138(1):45-50. 
6. Schara U, Mortier, Mortier W. Long-term steroid therapy in Duchenne muscular dystrophy-positive results versus side effects. J Clin Neuromuscul Dis. 2001;2(4):179-83.

7. King WM, Ruttencutter R, Nagaraja HN, Matkovic V, Landoll J, Hoyle C, et al. Orthopedic outcomes of long-term daily corticosteroid treatment in Duchenne muscular dystrophy. Neurology. 2007;68(19):1607-13.

8. DeSilva S, Drachman DB, Mellits D, Kuncl RW. Prednisone treatment in Duchenne muscular dystrophy. Long-term benefit. Arch Neurol. 1987;44(8):818-22.

9. Angelini C, Pegoraro E, Turella E, Intino MT, Pini A, Costa C. Deflazacort in Duchenne dystrophy: study of long-term effect. Muscle Nerve. 1994;17(4):386-91.

10. Silversides CK, Webb GD, Harris VA, Biggar DW. Effects of deflazacort on left ventricular function in patients with Duchenne muscular dystrophy. Am J Cardiol. 2003;91(6): 769-72.

11. Markham LW, Spicer RL, Khoury PR, Wong BL, Mathews KD, Cripe LH. Steroid therapy and cardiac function in Duchenne muscular dystrophy. Pediatr Cardiol. 2005;26(6):768-71.

12. Markham LW, Kinnett K, Wong BL, Woodrow Benson D, Cripe LH. Corticosteroid treatment retards development of ventricular dysfunction in Duchenne muscular dystrophy. Neuromuscul Disord. 2008;18(5):365-70.

13. Alman BA, Raza SN, Biggar WD. Steroid treatment and the development of scoliosis in males with Duchenne muscular dystrophy. J Bone Joint Surg Am. 2004;86-A(3):519-24.

14. Kinali M, Main M, Eliahoo J, Messina S, Knight RK, Lehovsky J, et al. Predictive factors for the development of scoliosis in Duchenne muscular dystrophy. Eur J Paediatr Neurol. 2007;11 (3):160-6.

15. Bonifati MD, Ruzza G, Bonometto P, Berardinelli A, Gorni K, Orcesi S, et al. A multicenter, double-blind, randomized trial of deflazacort versus prednisone in Duchenne muscular dystrophy. Muscle Nerve. 2000;23(9):1344-7.

16. Moxley RT, 3rd, Ashwal S, Pandya S, Connolly A, Florence J, Mathews K, et al. Practice parameter: corticosteroid treatment of Duchenne dystrophy: report of the Quality Standards Subcommittee of the American Academy of Neurology and the Practice Committee of the Child Neurology Society. Neurology. 2005;64(1):13-20

17. American Thoracic Society. Respiratory care of the patient with Duchenne muscular dystrophy. Am J Crit Care Med. 2004;170: 456-65.

18. American Academy of Pediatrics. Cardiovascular health supervision for individuals affected by Duchenne or Becker muscular dystrophy. Pediatrics. 2005;166(6): 1569-73.

19. TREAT-NMD.eu [homepage on the Internet]. United Kingdom. [cited 2009 Aug 17]. Available from: http://www.treatnmd.eu/userfiles/file/general/TREAT-NMD_DMD_ interim_recommendations.pdf

20. Bushby K BJ, Bullock R, Eagle M, Gibson M, Quinby J. The Multidisciplinary management of Duchenne muscular dystrophy. Curr Pediatr. 2005;15:292-300.

21. Muntoni F, Bushby K, van Ommen G. 128th ENMC International workshop on 'preclinical optimization and phase I/II clinical trials using antisense oligonucleotides in Duchenne Muscular Dystrophy' 22-24 October 2004, Naarden, The Netherlands. Neuromuscul Disord. 2005;15(6):450-7.

22. Griggs RC, Moxley RT, 3rd, Mendell JR, Fenichel GM, Brooke MH, Pestronk A, et al. Duchenne dystrophy: randomized, controlled trial of prednisone (18 months) and azathioprine (12 months). Neurology. 1993;43(3 Pt 1):520-7.

23. Backman E, Henriksson KG. Low-dose prednisolone treatment in Duchenne and Becker muscular dystrophy. Neuromuscul Disord. 1995;5(3):233-41.

24. Rahman MM, Hannan MA, Mondol BA, Bhoumick NB, Haque A. Prednisolone in Duchenne muscular dystrophy. Bangladesh Med Res Counc Bull. 2001;27(1):38-42.

25. Beenakker EA, Fock JM, Van Tol MJ, Maurits NM, Koopman HM, Brouwer OF, et al. Intermittent prednisone therapy in Duchenne muscular dystrophy: a randomized controlled trial. Arch Neurol. $2005 ; 62(1): 128-32$.
26. Reitter B. Deflazacort vs. prednisone in Duchenne muscular dystrophy: trends of an ongoing study. Brain Dev 1995; 17 Suppl: 39-43.

27. Reitter B. Motor performance of DMD boys treated with prednisone or deflazacort: interim results of a double-blind study [abstract]. Dev Med Child Neurol. 1995;37 Suppl 72:107.

28. Campbell C, Jacob P. Deflazacort for the treatment of Duchenne Dystrophy: a systematic review. BMC Neurol. 2003;3:7.

29. Manzur AY, Kuntzer T, Pike M, Swan A. Glucocorticoid corticosteroids for Duchenne muscular dystrophy. Cochrane Database Syst Rev. 2008(1):CD003725.

30. Merlini L, Cicognani A, Malaspina E, Gennari M, Gnudi S, Talim B, et al. Early prednisone treatment in Duchenne muscular dystrophy. Muscle Nerve. 2003;27(2):222-7.

31. Kinali M, Mercuri E, Main M, Muntoni F, Dubowitz V. An effective, low-dosage, intermittent schedule of prednisolone in the long-term treatment of early cases of Duchenne dystrophy. Neuromuscul Disord. 2002;12 Suppl 1:S169-74.

32. Bachrach LK. Taking steps towards reducing osteoporosis in Duchenne muscular dystrophy. Neuromuscul Disord. 2005;15 (1):86-7.

33. Biggar WD, Bachrach LK, Henderson RC, Kalkwarf H, Plotkin H, Wong BL. Bone health in Duchenne muscular dystrophy: a workshop report from the meeting in Cincinnati, Ohio, July 8, 2004. Neuromuscul Disord. 2005;15(1):80-5.

34. Tarnopolsky M, Mahoney D, Thompson T, Naylor H, Doherty TJ. Creatine monohydrate supplementation does not increase muscle strength, lean body mass, or muscle phosphocreatine in patients with myotonic dystrophy type 1. Muscle Nerve. 2004;29(1): 51-8.

35. Fowler EG, Graves MC, Wetzel GT, Spencer MJ. Pilot trial of albuterol in Duchenne and Becker muscular dystrophy. Neurology. 2004;62(6):1006-8.

36. Skura CL, Fowler EG, Wetzel GT, Graves M, Spencer MJ. Albuterol increases lean body mass in ambulatory boys with Duchenne or Becker muscular dystrophy. Neurology. 2008;70 (2):137-43.

37. Sharma KR, Mynhier MA, Miller RG. Cyclosporine increases muscular force generation in Duchenne muscular dystrophy. Neurology. 1993;43(3 Pt 1):527-32.

38. Fenichel GM, Griggs RC, Kissel J, Kramer TI, Mendell JR, Moxley $\mathrm{RT}$, et al. A randomized efficacy and safety trial of oxandrolone in the treatment of Duchenne dystrophy. Neurology. 2001;56(8):1075-9.

39. Stern LM, Fewings JD, Bretag AH, Ballard FJ, Tomas FM, Cooper DM, et al. The progression of Duchenne muscular dystrophy: clinical trial of allopurinol therapy. Neurology. 1981;31(4): 422-6.

40. Mok E, Letellier G, Cuisset JM, Denjean A, Gottrand F, Alberti C, et al. Lack of functional benefit with glutamine versus placebo in Duchenne muscular dystrophy: a randomized crossover trial. PLoS One. 2009;4(5):e5448.

41. Gamstorp I, Gustavson KH, Hellstrom O, Nordgren B. A trial of selenium and vitamin $\mathrm{E}$ in boys with muscular dystrophy. J Child Neurol. 1986;1(3):211-4.

42. Smith AD, Koreska J, Moseley CF. Progression of scoliosis in Duchenne muscular dystrophy. J Bone Joint Surg Am. 1989;71 (7):1066-74.

43. Miller F, Moseley CF, Koreska J. Spinal fusion in Duchenne muscular dystrophy. Dev Med Child Neurol. 1992;34(9):775-86.

44. Kurz LT, Mubarak SJ, Schultz P, Park SM, Leach J. Correlation of scoliosis and pulmonary function in Duchenne muscular dystrophy. J Pediatr Orthop. 1983;3(3):347-53.

45. Galasko CS, Delaney C, Morris P. Spinal stabilisation in Duchenne muscular dystrophy. J Bone Joint Surg Br. 1992;74(2):210-4.

46. Miller RG, Chalmers AC, Dao H, Filler-Katz A, Holman D, Bost F. The effect of spine fusion on respiratory function in Duchenne muscular dystrophy. Neurology. 1991;41(1):38-40.

47. Lankester BJA WM, Gargan MF. Duchenne muscular dystrophy. Curr Orthopaed. 2007;21:298-300

48. Shapiro F, Sethna N, Colan S, Wohl ME, Specht L. Spinal fusion in Duchenne muscular dystrophy: a multidisciplinary approach. Muscle Nerve. 1992;15(5):604-14. 
49. Marsh A, Edge G, Lehovsky J. Spinal fusion in patients with Duchenne's muscular dystrophy and a low forced vital capacity. Eur Spine J. 2003;12(5):507-12.

50. Bushby K, Muntoni F, Bourke JP. 107th ENMC international workshop: the management of cardiac involvement in muscular dystrophy and myotonic dystrophy. 7th-9th June 2002, Naarden, the Netherlands. Neuromuscul Disord. 2003;13(2):166-72.

51. Eagle M, Baudouin SV, Chandler C, Giddings DR, Bullock R, Bushby K. Survival in Duchenne muscular dystrophy: improvements in life expectancy since 1967 and the impact of home nocturnal ventilation. Neuromuscul Disord. 2002;12(10): 926-9.

52. Nigro G, Comi LI, Politano L, Bain RJ. The incidence and evolution of cardiomyopathy in Duchenne muscular dystrophy. Int J Cardiol. 1990;26(3):271-7.

53. Duboc D, Meune C, Lerebours G, Devaux JY, Vaksmann G, Becane HM. Effect of perindopril on the onset and progression of left ventricular dysfunction in Duchenne muscular dystrophy. J Am Coll Cardiol. 2005;45(6):855-7.

54. Ramaciotti C, Heistein LC, Coursey M, Lemler MS, Eapen RS, Iannaccone ST, et al. Left ventricular function and response to enalapril in patients with Duchenne muscular dystrophy during the second decade of life. Am J Cardiol. 2006;98(6):825-7.

55. Ishikawa Y, Bach JR, Minami R. Cardioprotection for Duchenne's muscular dystrophy. Am Heart J. 1999;137(5):895-902 .

56. Ogata H, Ishikawa Y, Ishikawa Y, Minami R. Beneficial effects of beta-blockers and angiotensin-converting enzyme inhibitors in Duchenne muscular dystrophy. J Cardiol. 2009;53(1):72-8.
57. Garg R, Yusuf S. Overview of randomized trials of angiotensinconverting enzyme inhibitors on mortality and morbidity in patients with heart failure. Collaborative Group on ACE Inhibitor Trials. JAMA. 1995;273(18):1450-6.

58. Gross R, Johnston K. Levels of evidence: taking neurology to the next level. Neurology. 2009;72:8-10.

59. Reitter B. 75th European neuromuscular centre international workshop: 2nd workshop on the treatment of muscular dystrophy, 10-12 December, 1999, Naarden, the Netherlands. Neuromusc Disord. 2000;10:313-20.

60. Corrado G, Lissoni A, Beretta S, Terenghi L, Tadeo G, FogliaManzillo $G$, et al. Prognostic value of electrocardiograms, ventricular late potentials, ventricular arrhythmias, and left ventricular systolic dysfunction in patients with Duchenne muscular dystrophy. Am J Cardiol. 2002;89(7):838-41.

61. Mirabella M, Servidei S, Manfredi G, Ricci E, Frustaci A, Bertini E, et al. Cardiomyopathy may be the only clinical manifestation in female carriers of Duchenne muscular dystrophy. Neurology. 1993;43(11):2342-5

62. Hoogerwaard EM, van der Wouw PA, Wilde AA, Bakker E, Ippel $\mathrm{PF}$, Oosterwijk JC, et al. Cardiac involvement in carriers of Duchenne and Becker muscular dystrophy. Neuromuscul Disord. 1999;9(5):347-51.

63. Willig TN, Bach JR, Venance V, Navarro J. Nutritional rehabilitation in neuromuscular disorders. Semin Neurol. 1995; 15(1):18-23. 